\title{
Value-Added Medical Education: Engaging Future Doctors to Transform Health Care Delivery Today
}

\author{
Steven Y. Lin, $M D^{7}$, Erika Schillinger, $M D^{2}$, and David M. Irby, $P h D^{3}$ \\ ${ }^{1}$ Center for Education and Research in Family and Community Medicine, Division of General Medical Disciplines, Department of Medicine, \\ Stanford University School of Medicine, Palo Alto, CA, USA; ${ }^{2}$ Center for Education and Research in Family and Community Medicine, Division of \\ General Medical Disciplines, Department of Medicine, Stanford University School of Medicine, Stanford, CA, USA; ${ }^{3}$ Office of Research and \\ Development in Medical Education and Department of Medicine, University of California San Francisco (UCSF), San Francisco, CA, USA.
}

KEY WORDS: medical education; practice-based learning; systems-based practice; primary care redesign.

J Gen Intern Med 30(2):150-1

DOI: $10.1007 / \mathrm{s} 11606-014-3018-3$

(c) Society of General Internal Medicine 2014

$\mathrm{M}$ edical student education typically aims to increase the supply of future physicians while ignoring current problems in health care delivery. This focus on the future fails to address the pressing challenges of today. These challenges include a shrinking ratio of adult primary care clinicians to population, a failure to address population health and the need for cost reductions, and medical training that prepares students to deal with patients, but not with teams and systems. ${ }^{1}$ Change is desperately needed to translate education into better health outcomes for all Americans today.

To achieve this change, significant reforms are needed in both practice redesign and medical education. One proposed solution to the capacity issue in primary care is to "share the care" with non-clinician health care team members and learners. ${ }^{1}$ Within this paradigm, an empowered team comprising of clinicians, non-clinicians (nurses, medical assistants, health educators), and learners share responsibilities so that all team members, operating at their maximum potential, contribute to the health of their patient panel.

We believe that sharing the care goes beyond addressing the capacity-demand problem and may serve as an ideal starting point for building a new vision for the future of medical education. What if every medical student starting in year one is embedded in a primary health care team and engaged in meaningful roles of providing care appropriate to their stage of training? What if, instead of just shadowing a physician in clinic, early medical students serve as health coaches, provide motivational interviewing to assist patients with behavior change, and participate in quality improvement projects? What if, even if they do not have the diagnostic or treatment skills to provide formal patient care yet, early medical students are trained to do population health management and can reach out to patients overdue for routine preventive (pap smears, colonoscopies, mammograms) and chronic care services (foot

Published online September 13, 2014 and eye exams for diabetics)? This model of medical training is not only aligned with many of the recommendations of the Carnegie Foundation report ${ }^{2}$ - outpatient-focused, teambased, and patient-centered - but can add valuable capacity to our health care delivery system without changing the current infrastructure of academic health centers.

We call this "value-added medical education," where powerful experiential learning experiences can also add value and capacity to our health care delivery system. This can be achieved by training and involving medical students in targeted patient care tasks. Students are eager to engage in care and take on responsibilities as part of the health care team in ways that do not generate duplicative work or consume additional energy from the clinical faculty. The underlying principles of value-added medical education are entirely compatible with the Institute of Medicine's framework for a Learning Health System, and has been championed by leaders like Thomas Bodenheimer, ${ }^{1}$ Kevin Grumbach, ${ }^{3}$ and others who have already piloted a number of innovative programs that combine education and care in creative and synergistic ways.

At the University of California, San Francisco, where much of the pioneering work on value-added medical education has been done, students and faculty members are working together to reboot their curriculum by creating authentic workplace learning experiences that leverage the talents and commitments of every student to add value to the care of patients today. Other schools are also testing new methods of providing real world opportunities for trainees to participate in improving the quality of the health systems in which they work and study. The Health Professions Education Collaborative, sponsored by the Institute for Healthcare Improvement, helps drive curricular changes that promote team-based continuous quality improvement initiatives at 16 academic health centers.

Stanford University School of Medicine is also embedding some first year medical students in community health centers where they provide care through health coaching, motivational interviewing, and patient education delivered via longitudinal primary care community partnerships. Early medical students can participate in a patient navigator program to guide patients hospitalized with congestive heart failure through the discharge process, make follow-up telephone calls after they 
leave the hospital, and provide a supervised home visit to ensure patient safety and reduce preventable readmissions. In our free clinics, students are serving as referral coordinators and insurance counselors to educate uninsured patients about the Affordable Care Act and place them in medical homes as part of a bridge-to-care initiative. A scribe program designed to turn early trainees into clinical documentation experts has the potential to change our primary care clinics into highperforming practices, while equipping students with the technological skills needed to practice medicine in the electronic medical record era. All these programs are similar in that they balance the often conflicting missions of education and patient care by merging these two objectives into a single pursuit.

We are not the first to advocate for engaging medical students in systems improvement as an essential part of education reform. We echo the call of leaders like Catherine Lucey, ${ }^{4}$ who has written for all medical schools to "explicitly commit to implementing educational programs that measurably improve health care today while educating the physicians of tomorrow." We add to her charge by arguing that value-added educational redesign is not only desirable to produce 21 st century physicians able to achieve better health outcomes for the American people, but necessary as an immediate solution to address the growing imbalance between population demands for medical care and our capacity to provide care. We need solutions that can work right now, not decades into the future. There are more than 80,000 students in U.S. medical schools today. ${ }^{5}$ Harnessing their collective engagement and untapped capacity for patient care would be transformative.

Transforming this dream into reality will take leadership, redeployment of resources, and curricular redesign. Leadership is needed to articulate the vision, generate urgency for change, shift resources, provide faculty development, and build partnerships with new clinical training sites. This will require some redirection of existing resources currently devoted to early clinical training, including patient communication and physical exam courses. Value-added education programs have the potential to fuel clinical partners' interest in having early medical students at their sites, since they are actively engaged in patient care tasks that contribute to the health of their patient populations. These partners may need to adjust workflow and space to accommodate their new medical student team members. At the same time, early clinical training courses will need to prepare their students with the knowledge and skills to take on meaningful responsibilities as part of the health care team, including motivational interviewing, health coaching, and population health management. Medical school course directors, clinical faculty, and community preceptors will need to communicate in order to enable integration between course knowledge and real world skills. Faculty and staff development will be needed in order to reimagine the clinical experience for students and provide the clinic staff with skills to actively involve students in their daily work. Curricular innovation and redesign will be essential to offer opportunity space for these new experiences and skills. However, none of these factors is insurmountable, especially in light of the social good derived from student learning and engagement in improving health care delivery.

A vision for a new kind of medical education is taking shape. We believe that the principles of value-added medical education should and will play an important role in this revolution. These principles include: (1) early integrated workplace learning for all medical students, (2) an interprofessional teambased quality improvement culture to promote understanding and respect of non-clinician providers, (3) collaborative and data driven population health management, (4) optimization of professional roles that are learner-centered and continuously adjusted to changing stages of development, and (5) the fusion of robust experiential learning experiences with the delivery of high-performing, patient-centered primary care. The challenge now is to make value-added training a standard part of the curriculum in every medical school. We can do this by taking lessons learned from successful pilots and implementing them widely with the support of professional organizations and accrediting bodies. It is time to share the care with our future colleagues.

\section{Acknowledgements:}

Contributors: All authors listed have contributed sufficiently to the project to be included as authors, and all those who are qualified to be authors are listed in the author byline.

Funders: None.

Prior Presentations: None.

Conflict of Interest: There are no conflicts of interest to report.

Corresponding Author: Steven Y. Lin, MD; Center for Education and Research in Family and Community Medicine, Division of General Medical Disciplines, Department of MedicineStanford University School of Medicine, 211 Quarry Road, Suite 405, MC 5985 94304, Palo Alto, CA, USA (e-mail: stevenlin@stanford.edu).

\section{REFERENCES}

1. Bodenheimer T, Pham HH. Primary care: current problems and proposed solutions. Health Aff (Millwood). 2010;29:799-805.

2. Cooke M, Irby DM, O'Brien BC. Educating Physicians: A Call for Reform of Medical School and Residency. San Francisco, CA: Jossey-Bass; 2010.

3. Grumbach K, Lucey CR, Johnston SC. Transforming from centers of learning to learning health systems: the challenge for academic health centers. JAMA. 2014;311(11):1109-10.

4. Lucey CR. Medical education: part of the problem and part of the solution. JAMA Intern Med. 2013;173(17):1639-43.

5. Association of American Medical Colleges. Total Enrollment by U.S. Medical School and Race and Ethnicity, 2011. https://www.aamc.org/download/ 160146/data/table 31-enrll-race-sch-2011.pdf. Accessed May 20, 2014. 